\title{
Research on Operation Management Innovation of New-Type R \& D Institution in Anhui Province in China
}

\author{
Hui Xia, Zhangzhi Ge \\ School of Public Affairs, University of Science and Technology of China, Hefei, China \\ Email: gezhangzhi2008@163.com
}

How to cite this paper: Xia, H. and Ge, Z.Z. (2019) Research on Operation Management Innovation of New-Type R \& D Institution in Anhui Province in China. Open Journal of Business and Management, 7, 263-274.

https://doi.org/10.4236/ojbm.2019.71018

Received: October 16, 2018

Accepted: January 15, 2019

Published: January 18, 2019

Copyright (c) 2019 by authors and Scientific Research Publishing Inc. This work is licensed under the Creative Commons Attribution International License (CC BY 4.0).

http://creativecommons.org/licenses/by/4.0/

\begin{abstract}
In order to solve the problem of transformation of scientific and technological achievements, new research and development institutions are being vigorously constructed all over the country. A number of new research and development institutions have been also established in Anhui Province in recent years. It is of great significance to clarify the operation and management mechanism of new R \& D institutions for promoting the development of new $\mathrm{R}$ \& D institutions. With the help of case analysis and field investigation, this paper selects typical new R \& D institutions in Anhui Province as the research object, and combines with quantitative analysis of relevant data. The main conclusions are as follows: The construction of new R \& D institutions in Anhui is of great significance, however, at present, there are still many problems in the efficiency of operation and management, such as unclear development orientation, inadequate talent introduction and so on. These problems have hindered the further development of new R \& D institutions. Finally, in view of the above problems, drawing on the relevant experience of new R \& D institutions at home and abroad, some policy recommendations are put forward.
\end{abstract}

\section{Keywords}

New-Type R \& D Institution, Operation Management, Innovation Development

\section{Introduction}

At the end of 2015, China definitely put forward five development concepts namely innovative development, coordinated development, green development, open development and shared development, where innovation development 
ranks first among them [1]. Under this background, in order to implement the Innovation-Driven Development Strategy which has put into effect since the end of 2012 in the whole country, Anhui province focuses on strengthening the construction of an innovative province in recent years, and a number of new-type $\mathrm{R}$ \& D institutions have been established with a view to providing impetus for Anhui's innovation development. Although these various forms of new-type R \& $\mathrm{D}$ institutions have effectively led to cross-regional and cross-industrial combinations of innovation elements, forming a new strategic, integrated, adaptive and innovative organization mode and innovation ecology [2], they still have some deficiencies in development orientation, assessment mechanism, talent introduction, R \& D efficiency, achievement transformation and the promotion of industrial economic development. By choosing and analyzing the mature operation and management methods of the advanced new-type R \& D institutions in China, we can provide useful experience for the development of the new-type $\mathrm{R}$ \& D institutions in Anhui Province, and find out the countermeasures and suggestions to improve the operation and management effectiveness of them in Anhui Province, so as to promote their further development.

For a long time, there has always been a certain gap between $S \& T$ achievements and market demand in China. The phenomenon of "two layers of skin" in $\mathrm{S} \& \mathrm{~T}$ and the economy has been criticized by all circles. This to some extent also reveals the fact that the transformation rate of $S \& T$ achievements is low in China. If the transformation of $\mathrm{S} \& \mathrm{~T}$ achievements cannot be completed, those achievements can only be regarded as an unavailable resource rather than an asset, which is actually a huge waste of $S \& T$ resources. The transformation problem of the $S \& \mathrm{~T}$ achievements is a century-long problem. In order to solve this problem, various circles have made various attempts, promoting the construction of new research and development institutions have become a powerful measure. The core function of the new-type $\mathrm{R} \& \mathrm{D}$ institution is to realize the integration of $\mathrm{R} \& \mathrm{D}$ and transformation of $\mathrm{S} \& \mathrm{~T}$ achievements, breaking the boundary between $\mathrm{R} \& \mathrm{D}$ and transformation of traditional scientific research institutions, and taking the responsibility of exploring a new model for the transformation of S \& T achievements [3].

\section{The Reasons for Improving Operational Efficiency of New R \& D Institutions}

New-type R \& D institution is an important force in transferring $S \& T$ achievements in Anhui Province. At the same time, it is also an important attempt to strengthen the construction of innovative province and implement the national strategy of innovation-driven development. Enhancing the effectiveness of its operation and management is the key to fully exert its own role.

\subsection{Promoting the Construction of Innovative Province and Realizing Innovation-Driven Development}

Since the national strategy of innovation-driven development was put forward, 
all parts of the country have been actively exploring and promoting the upgrading of $S \& T$ innovation model and the practice of $S \& T$ industrialization. Among these, establish new-type R \& D institutions have become an important measure in promoting innovation and development. The practical experience also shows that the new-type $\mathrm{R} \& \mathrm{D}$ institutions are indeed a brand-new industrial R \& D model. The new-type R \& D institution not only helps to strengthen the basic common technology research and development, but also plays an important role in the research and development of industrial technologies. It can effectively improve the level of regional S \& $\mathrm{T}$ innovation and economic development, so as to achieve development with innovation.

\subsection{Promoting the Optimization of Industrial Structure and the Development of Strategic Emerging Industries in Anhui}

Anhui Province, especially the provincial capital Hefei as one of the four major science and education cities, has a large number of universities, research institutes, and R \& D companies. Although the scientific research strength is strong, but the role of $\mathrm{S} \& \mathrm{~T}$ innovation in promoting industrial development is not obvious, scientific research and industry have not been well integrated. The emergence of new-type R \& D institutions can effectively integrate all kinds of S \& T innovation resources in Anhui, and actively aim at the breakthrough and innovation of common and key technology of strategic emerging industries in Anhui province. It helps to realize the effective links among innovation, industry and capital between $\mathrm{S} \& \mathrm{~T}$ innovation and industrial development, finally become a bridge linking $S \& T$ and economy leading the new breakthrough point of regional industrial transformation and upgrading and development, effectively driving the development of strategic emerging industries [4].

\subsection{Breaking the Limitation of the Operation and Management Mechanism of Traditional Scientific Research Institutions and Stimulating Innovation Vitality}

Because of its inherent official or semi-official nature, the operation and management mechanisms of traditional $\mathrm{R} \& \mathrm{D}$ institutions are more or less contains official nature. The long-term existence of this dilemma makes such research institutions insensitive to the market, not interested in industrialization, research and development activities do not respond to market demand, and the utilization of innovative achievements is low. The emergence of new-type R \& D institutions with multi-party participation in $\mathrm{R} \& \mathrm{D}$ mode enables different $\mathrm{R} \& \mathrm{D}$ forces to exchange and collide, and ultimately realizes the burst of innovation vitality of all parties, ultimately realizing the innovation and vitality of all parties. At the same time, the participation of multi-agent is bound to adopt a mechanism of operation management which is different from traditional scientific research institutions to clearly divide the rights, responsibilities and interests of all parties is also helpful to break the operation and management mechanism solidified by traditional scientific research institutions and further stimulate the 
vitality of innovation.

\section{The Dilemma of Anhui Province's New-Type R \& D Institutions}

New-type R \& D institutions play an important role in technological innovation, industrial transformation and upgrading and economic development in Anhui Province. Its development prospect is good; however, the development process is not yet complete. In particular, it still has many operational management difficulties.

\subsection{The Orientation Is Not Clear and the Identity Is Unconfirmed}

The development orientation is the base of an institution. At present, the development orientation of the new-type R \& D institutions in Anhui Province is still not clear. At the same time, it leads to the homogenization of the new-type R \& D institutions in Anhui Province. Take the 11 (In September 2018, the number increased to 20 , see Table 1 ) newly approved $\mathrm{R} \& \mathrm{D}$ institutions approved by the

Table 1. The first batch of new research and development institutions in Anhui Province.

\begin{tabular}{|c|c|c|}
\hline No. & Unit name & Administrative department \\
\hline 1 & University of Science and Technology of China Institute of Advanced Technology Research & Hefei Science and Technology Bureau \\
\hline 2 & Hefei University of Technology Intelligent Manufacturing Technology Research Institute & Hefei Science and Technology Bureau \\
\hline 3 & Chinese Academy of Sciences (Hefei) Technology Innovation Engineering Institute Co., Ltd. & Hefei Science and Technology Bureau \\
\hline 4 & Hefei Institute of Public Safety, Tsinghua University & Hefei Science and Technology Bureau \\
\hline 5 & Anhui Institute of Industrial Technology Innovation & Hefei Science and Technology Bureau \\
\hline 6 & Hefei Institute of Low Temperature Electronic & Hefei Science and Technology Bureau \\
\hline 7 & Anhui Popular Science Products Engineering Research Center Co., Ltd. & Hefei Science and Technology Bureau \\
\hline 8 & Hefei Gaowei Data Technology Co., Ltd. & Hefei Science and Technology Bureau \\
\hline 9 & Wuhu Hart Robot Industry Technology Research Institute Co., Ltd. & Wuhu Science and Technology Bureau \\
\hline 10 & $\begin{array}{l}\text { China Electronic Technology Group Wuhu General Aviation Industry Technology Research } \\
\text { Institute Co., Ltd. }\end{array}$ & Wuhu Science and Technology Bureau \\
\hline 11 & Wuhu Anpu Robot Industry Technology Research Institute Co., Ltd. & Wuhu Science and Technology Bureau \\
\hline 12 & Wuhu Saibao Information Industry Technology Research Institute Co., Ltd. & Wuhu Science and Technology Bureau \\
\hline 13 & Wuhu United New Energy Heavy Truck Industry Technology Research Institute Co., Ltd. & Wuhu Science and Technology Bureau \\
\hline 14 & Wuhu Intelfil Biological Products Industry Research Institute Co., Ltd. & Wuhu Science and Technology Bureau \\
\hline 15 & Anhui Kuwa Robot Co., Ltd. & Wuhu Science and Technology Bureau \\
\hline 16 & Anhui Xiangyuan Safety Environmental Science and Technology Co., Ltd. & Bengbu Science and Technology Bureau \\
\hline 17 & Anhui Houqingchun Industrial Design Research Institute Co., Ltd. & Bengbu Science and Technology Bureau \\
\hline 18 & AnqingBeihua Science Park Co., Ltd. & Anqing Science and Technology Bureau \\
\hline 19 & Anhui Weiwei Academy of Vibration and Noise Reduction Technology & Anqing Science and Technology Bureau \\
\hline 20 & Wanjiang Emerging Industry Technology Development Center & Tongling Science and Technology Bureau \\
\hline
\end{tabular}

(http://www.ahkjt.gov.cn/content/detail/5b99d5457f8b9aac29052dfd.html) 
Anhui provincial S \& T department in 2015 as an example, the single-subject positioning blur and the overall positioning are highly similar exist at the same time. This not only makes new-type R \& D institutions lack their own characteristics and advantages, but their practical role is not obvious, and homogeneity research also causes a waste of S \& T resources. Moreover, there are many different understandings and even controversies in many issues, such as what is the difference and same point in the development mode compared to the traditional university science technology park incubator and technology transfer center? How about its role in the $\mathrm{S} \& \mathrm{~T}$ innovation system and industrial development and how to adjust the regional economic structure and transform the industry [5]?

In addition, there is no statement about the role of the new-type $\mathrm{R} \& \mathrm{D}$ institution in China's existing $S \&$ T development plans and innovation systems. At present, only the Ministry of S \& T of Anhui Province announced in 2015 the first batch of 11 newly approved R \& D institutions and the notification of the evaluation of new-type R \& D institutions issued in 2017. The identity of the scientific research institutions of new-type R \& D institutions in Anhui Province has not been clearly recognized. The lack of identity makes it unable to enjoy corresponding supporting measures. For example, the private non-enterprise type of new-type R \& D institutions are often confined to their own public welfare nature, which can neither rely on profits to support as enterprises, nor enjoy the same number of preferential policies and adequate financial input as state-owned scientific research institutions. The scale of scientific research funds is far from meeting the actual needs [6].

\subsection{The Assessment System Is Not Clear and the Responsibility Is Ambiguous}

Some new-type R \& D institutions that are cooperatively built by some colleges and universities and the government implemented the "three-no" management system, which means do not give management personnel grades, funds and preparations. Those personnel are mainly drawn from colleges or government agencies, and the personnel management of the deployment personnel is still in the original unit. The purpose of doing so was originally to be more flexible in managing and operating new-type $\mathrm{R} \& \mathrm{D}$ institutions and to reduce management costs. However, in actual operation, the rank and salary of the personnel under the "three-no" system still come from the original unit, which has nothing to do with the effectiveness of the operation and management of the new-type $R$ $\& \mathrm{D}$ institution. The positive incentive effect is not strong, resulting in the deployment of personnel who do not fully invest in the management and development of new-type R \& D institutions, resulting in a low efficiency of the work. At the same time, because the personnel management still in the original unit, it means that they will not respond effectively to negative incentives. Because as long as there is no big fault, they can still enjoy the treatment of the original unit as before, which result to locate and pursue responsibility become difficult. 


\subsection{The Talent Introduction Is Not Perfect and High-Level Talent Is Scarce}

The new-type R \& D organization focuses on innovation, which can generate new technological breakthroughs and promote the emergence of new industries [7]. This has a high requirement for the original innovation capability or reinvention ability of new-type R \& D institutions. Innovation mainly depends on talents, so embracing enough innovative talents for a new-type R \& D institution is extremely important. According to statistics, out of the proportion of overseas high-level scientific research talents introduced in Anhui province by 2013, Hefei has an absolute advantage which up to $90 \%$. This is the inevitability of Hefei as a four major science and education city, but it also reflects the fact that the overall talent pool of the new-type R \& D institutions in Anhui Province is not balanced, and the strength of $\mathrm{R} \& \mathrm{D}$ in some cities is weak. What is more, the high level of innovative talent in some cities is basically zero, which is extremely detrimental to its development.

Even Hefei, which has done relatively well in the introduction of talents at home and abroad, still has the problem of the low quality of imported innovative talents and the lack of foreign talents. Take the Institute of Advanced Technology, University of Science and Technology of China for example (abbreviated as "IAT"), although the IAT has also vigorously introduced high-level talents in the "Thousand Talents Program" and "Youth Thousand Talents Program", it has recruited key corporate management and technical experts and well-known scholars and professors from overseas universities as part-time tutors. The result of the introduction of overseas high-level talents is not obvious. There is no leading R \& D team from developed countries such as United States, Britain and Canada top research institutes such as the to carry out cross-disciplinary frontier research, lack of motivation to pursue independent innovation and original innovation, and lack of international technology complementarity and integration research.

\subsection{The Output Rate Is Low and Failed to Drive the Development of Economy}

Although the development of new-type R \& D institutions in Anhui has been considerable in recent years, the actual output benefit is not obvious. Similarly, take the IAT as an example, from the date of establishment in 2012, as of October 2017, there were only 140 patents applied for and granted, and according to the five-year period, there were less than 30 items each year. The IAT is established in accordance with the principle of "provincial college cooperation, city and school co-construction". Under this principle, it can be said that the Pioneer Research Institute has better support conditions compared to other new-type $\mathrm{R}$ \& D institutions in Anhui province, whether in terms of policy, funding, or talent. Looking back on achievements number of Shenzhen Kuang-Chi Institute of Technology, we can see clearly that the output efficiency of IAT is extremely 
low. The number of applications and patents granted in the same period reached 4200 , averaging 25 per week, almost equal to the number of one-year applications and patents granted by the IAT. Looking from the establishment time of the new-type R \& D institutions at home and abroad, the IAT was set up late, but it did not make good use of the advantages of mature experience, and at present, its $S \& T$ achievements output efficiency in a short period of time cannot see the trend of rapid improvement. The original intention of establishing a new-type $\mathrm{R} \& \mathrm{D}$ institution was to break through the plight of research and economics. However, from the current situation, the research activities of the new-type R \& D institutions in Anhui Province have not yet formed a supporting role in promoting industrial economic development.

\section{Countermeasures for Promoting the Operation and Management Efficiency of New-Type R \& D Institutions in Anhui}

Combined with the practical difficulties of operation and management of new-type R \& D institutions in Anhui Province, after analyzing the operational management methods of mature new-type $\mathrm{R} \& \mathrm{D}$ institutions at home and abroad, in order to break through the predicament, the new-type $\mathrm{R} \& \mathrm{D}$ institutions in Anhui Province should actively learn from the mature experience and find out the operation and management system suitable for their own characteristics. In the future development, they should focus on the following aspects.

\subsection{Accurately Positioning the Development Direction of the New-Type R \& D Institutions}

The new-type R \& D institutions in Anhui Province need to learn from the positioning strategies of relevant institutions at home and abroad, and work out the development positioning which is in line with their own characteristics. The positioning of new-type R \& D institutions needs to focus on ambitious goals and avoid short-sightedness. The government must take effective measures and implement comprehensive policies to guide Anhui's new-type R \& D institutions to actively conduct innovative research around the local and even the national strategically emerging industries that are desperately needed while ensuring their survival and development. Do not be too eager to pursue the current economic benefits and make the scientific research carried out short, flat and fast. While pursuing reasonable financial and economic indicators, it should also guide all types of new-type R \& D institutions to pay attention to basic, forward-looking and public welfare research. Focusing on the urgent needs of the industry and core technologies, we are committed to promoting the adjustment and optimization of regional economic structure and building itself into an innovation platform with a high concentration of innovation factors [8].

From the strategic point of view, the new-type R \& D institutions in Anhui Province should be the leader in the R \& D and application development of stra- 
tegic emerging industries in the province, and gradually grow from participants to leaders. From the perspective of function orientation, the new-type R \& D institutions in Anhui Province need to expand their functions precisely according to the characteristics of the region, grasp the characteristics of strong regional innovation strength, intensive research institutes and large scientific installations, and focus on the transformation of the major original innovation achievements in Anhui Province. Combining the status quo of strategic emerging industries in Anhui Province, we are committed to the research and innovation of some common industry technologies and key technologies in this field [9]. Scientific positioning can not only break the traditional $\mathrm{R} \& \mathrm{D}$ institutions confusion of social responsibility, assessment objectives are complex and other drawbacks, but also the new-type R \& D institutions to guide the efficient research efficiency. At the same time, the relevant departments of the Anhui Provincial Government should actively create a good development environment for the new-type R \& D institutions in Anhui Province and do a good job of supporting the relevant policies, funds, and services, and focus on the introduction and cultivation of innovative talents. It is imperative to step up research, formulate and implement relevant detailed rules for promoting the development of new-type R \& D institutions, and do well in the identification and management of new-type R \& D institutions [10], to give the new R \& D institution a clear identity of scientific research institution so as to clarify its right, status, nature and function, and to give it appropriate preferential treatment in strict accordance with relevant policies. For example, provincial-level financial science and technology projects can be established to support key projects of new-type R \& D institutions to improve R \& D levels and capabilities [11] [12]. Strengthen service awareness, actively resolve the difficulties and obstacles in the development process of new-type R \& $\mathrm{D}$ institutions, and form a joint force to promote the further development of new-type R \& D institutions.

\subsection{Discarding Administrative Assessment Method and Strengthening Market-Oriented Evaluation Mechanism}

The essence of the new-type $\mathrm{R} \& \mathrm{D}$ institutions is that the market determines the allocation of technological resources. Therefore, the assessment of new-type R \& $\mathrm{D}$ institutions should not be based on the assessment methods of traditional scientific research institutions. The measures of market economy should be the main method of assessment for new-type R \& D institutions. At the same time, there should also be some necessary administrative measures for overall consideration. We should adjust the organizational structure, operation mode and innovation field of new-type R \& D institutes with market orientation, insist on taking market orientation in scientific innovation and transformation of achievements, and truly serve the development of regional economic industry accurately. The service targets of new-type R \& D institutions are mainly enterprises. Therefore, in reality, the entrusted projects of companies often have more than 
government projects. The structure of such $\mathrm{R} \& \mathrm{D}$ projects determines that the economic income of R \& D personnel in new-type R \& D institutions mainly comes from market companies [13]. Therefore, in the assessment of new-type $\mathrm{R}$ \& D institutions, it is necessary to highlight the amount of funds invested by the $\mathrm{R} \& \mathrm{D}$ project in the market, the economic returns from the research results, and the benefits of the research results for the service targets. In order to ensure that the research activities of scientific research and results transformation of new-type R \& D institutions are closely related to the needs of the market, the fundamental purpose of economic and social development in the service area is achieved. In this aspect, can learn the project leader system of Kuang-Chi institute, implement project-centred process oversight, results-oriented outcome evaluation to encourage new-type R \& D institutions to continuously improve research and development efficiency [14]. At the same time, it encourages the participation of private capital in the construction and operation of the organization, and eventually realizes private capital as the leading factor in the construction of new research and development institutions, and fully realizes the market-oriented operation mechanism [15].

\subsection{Innovating Talent Introduction Mechanism to Enhance Innovation Ability}

Actively create a good scientific research environment that attracts talents, aims to attract and retain talents with a sound employment mechanism, a good working environment, generous remuneration packages, and bright development prospects. The changeable market demand requires that new-type $\mathrm{R} \& \mathrm{D}$ institutions must have strong innovative strength, so that they can have a place in the future development. High-quality innovative talents are the basis of their development. If the new-type R \& D institutions in Anhui Province want to have a greater promotion in the future development, they must adhere to the close combination of production, teaching and research, and give play to their own advantages. Various measures should be taken to introduce and cultivate top-notch and compound innovative talents who are proficient in scientific research, technological research and development, and have strong desire for innovation and entrepreneurship, so as to form a talent highland and better support the construction of Anhui independent innovation system. This point can learn from the practice of international cooperation and research and development of Shenzhen BGI Gene. While making full use of the advantages of Anhui Province, especially Hefei, the provincial capital, as a famous city of science and education, we should also actively carry out overseas distribution. By cooperating with overseas universities and scientific research organizations, we can improve the scientific research ability of new-type R \& D institutions in Anhui Province. Through a multi-participation joint training model, the reserve of talents will be strengthened; intensify the introduction of innovative talents to attract top innovative talents at home and abroad so that it will not only rapidly enhance current R \& D strength, but also guarantee future innovation capabilities of R \& D. 


\subsection{Respecting the Rules of $R \& D$ and Market and Improving R \& D Efficiency}

First of all, it needs to be clear that the first priority of new-type R \& D institutions is the R \& D innovation of S \& T achievements, which determines that they must strictly abide by the universal laws of scientific research. Therefore, in order to increase the efficiency of scientific research output, Anhui's new-type R \& $\mathrm{D}$ institutions must fully respect the law of scientific research and act according to the law. The R \& D entities within the organization are committed to the research and development of common emerging technologies and key technologies in strategic emerging industries. In order to focus on the key and difficult issues of $\mathrm{R} \& \mathrm{D}$, they must earnestly respect objective scientific research disciplines, guard against arrogance and prudence, and strive to achieve success. Scientific research must not deviate from its essence and only pursue surface results. Therefore, new-type R \& D institutions must avoid the induction of external short-term unsustainable projects, conduct independent scientific research, and concentrate on research and development.

Secondly, we must realize that as the main service target of new-type $R \& D$ institutions, the company determines that only a new type of $\mathrm{R} \& \mathrm{D}$ institution according to market rules can achieve sustainable development. The level of $\mathrm{R} \&$ $\mathrm{D}$ efficiency is also related to the degree of fit of $\mathrm{R} \& \mathrm{D}$ activities and market demand. Higher demand can bring high R \& D efficiency, therefore, the new-type $\mathrm{R} \& \mathrm{D}$ institutions need to pay attention to following the objective laws of the enterprise's own development and market economy operation to ensure that the new-type $\mathrm{R} \& \mathrm{D}$ institutions are flexible in operation, independent in management, and open to development, effectively respond to actual needs, and meet the needs of industrial development. In personnel exchanges and technical cooperation, must adhere to market orientation, deepen cooperation with various research institutes, universities, and governments and enterprises, build open and cooperative innovation networks, increase research output, and form a support for the industry and even the province's industrial economic development [16]. But on the other hand, new-type R \& D institutions should also take a long-term perspective, remembering that they are pursuing financial indicators and ignoring the frontier and strategic requirements of research. Establish a complete and flexible exit mechanism, grasp industry trends and directions, and timely withdraw from low-value, uncertain research projects.

In addition, it is also the key to improve the efficiency of $\mathrm{R} \& \mathrm{D}$ output to evaluate the efficiency and benefit of the output of new R \& D institutions. We should establish a result-oriented evaluation mechanism and give full play to the role of performance evaluation in promoting $\mathrm{R} \& \mathrm{D}$ activities and achievements. Here we can draw lessons from the expert evaluation method of the Franc Hoff Association and engage academic committees from outside by new R \& D institutes for peer review [17]. At the same time, we should lay particular emphasis on the evaluation and analysis of innovation input, innovation output and innovation performance, so as to find out the problems and solve them pertinently 
so as to improve efficiency [18].

\subsection{Implementing Intellectual Property Strategy Management to Enhance the Enthusiasm of R \& D Innovation}

In order to increase the efficiency of new-type R \& D institutions, it is necessary to strengthen market supervision from the side and maintain the market order so as to provide a good external market environment for the research and innovation activities of new-type $\mathrm{R} \& \mathrm{D}$ institutions. New-type $\mathrm{R} \& \mathrm{D}$ institutes often produce more high and new technology achievement, emphasizing on the management and application of intellectual property rights of related technical achievements is a strong guarantee for their own sustainable development [19]. Active measures should be taken to protect the innovative and practical achievements of new-type R \& D institutions in the fields of industrial common technology and key technology so as to give full play to the role of intellectual property rights in independent technological innovation. From the source innovation to the technological evolution path and key links of the transformation of S \& $\mathrm{T}$ achievements, the strategic layout of S \& T research and development should be carried out. By applying for patents with innovative results, consciously form itself own dominant position in this and related fields, strive to quickly realize the strategic patent coverage of the underlying technology in this field, fully protect the intellectual property rights of the innovative achievements of new-type R \& $\mathrm{D}$ institutions, to maintain their legitimate economic benefits [20]. This will not only bring clear return to investors, but also help new-type R \& D institutions to get more R \& D investment. Only by doing a good job in the benefit distribution and safeguard measures of scientific research output can we provide researchers with an atmosphere of devoting themselves to scientific research, ensure the smooth and effective development of scientific research activities, and thus enhance their enthusiasm for scientific research.

\section{Acknowledgements}

This work was supported by General Financial Grant from the China Postdoctoral Science Foundation, Grant Number: 2017M622029.

\section{Conflicts of Interest}

The authors declare no conflicts of interest regarding the publication of this paper.

\section{References}

[1] Zou, J. and Meng, F.Y. (2017) Of the Five Development Ideas. Journal of Nanchang Normal University (Social Sciences), 1, 18-22.

[2] Liao, X.D. (2017) Research on Construction of New Research and Development Institutions in Guangdong from Perspective of Innovation System Competition Science \& Technology and Economy, 4, 41-45

[3] Yang, B.W. and Tu, P. (2018) A Research on the Evaluation Index System of New 
Research Institutions in Beijing. Science Research Management, 3, 82-86.

[4] Cheng, G.S. and Rui, M.J. (2013) The New Advancement of Theoretical Research of the Strategic Emerging Industries. Journal of Business Economics, 8, 75-83.

[5] Pan, Y. and Xu, Y. (2015) Analysis of the Status Quo of the Development of New-Type R \& D Institutions in Anhui Province and Countermeasures Research. China Science and Technology Information, 15, 120-122.

[6] Xia, T.S., Zhang, Y.F., Gao, Y.H., Zhou, W.K. and Wang, C.L. (2014) Research on Collaborative Innovation Model and Mechanism of New-Type R \& D Institutions in China. Science \& Technology Progress and Policy, 14, 13-18.

[7] Li, M. (2017) Enlightenment on New Research and Development Institutions by Haier Open Partnership Ecosystem. Science and Technology Management Research, 17, 124-130.

[8] Liu, L. (2015) Research on the Background and Development Path of Strategic Emerging Industries in Anhui Province. Science \& Technology Economy Market, 12, 44-45.

[9] Zhu, J.J., Cai, J.W., Liu, S.F., Fang, Z.G. and Guan, Y.Q. (2013) Research on Operation Mechanism and Construction Strategy of New-Type R \& D Institutions in Jiangsu Province. Science \& Technology Progress and Policy, 14, 37-39.

[10] Wu, W. and Yin, L. (2016) Pasteur Quadrant Orientation Model and Function Location of New R \& D Institution. Technology Economics, 8, 38-44.

[11] Tan, H.B. (2012) Research and Thinking on New-Type R \& D institutions. Anhui Science \& Technology, 10, 19-21.

[12] Chen, B.M., Liu, G.W. and Ding, M.L. (2013) Research on the Development Status and Policy Recommendations of Chinese New-Type R \& D Organization. Forum on Science and Technology in China, 3, 27-31.

[13] Zhang, X.C., Jiang, H., Zhang, W. and Zi, Z.H. (2017) Comparison and Research of New Scientific Research Institutions at Home and Abroad. Science and Technology Management Research, 19, 108-109.

[14] Li, D.L. (2014) Exploring the Development Model and Characteristics of New-Type R \& D Institutions in Guangdong. Guangdong Science \& Technology, 23, 77-80.

[15] Chen, H.X., Jiang, C., Yuan, Y. and Wang, S.B. (2018) Research on the New R \& D Institutions Technology Transfer Based on New Pasteur Quadrant-An Empirical Study in JITRI. Science \& Technology Progress and Policy, 11, 36-45.

[16] Liao, Y.N. (2016) Research on New R \& D Institutions in China-Take Guangdong for Example. Science \& Technology Industry of China, 8, 70-76.

[17] Li, X.X. (2004) Evaluation Practice and Enlightenment of German Scientific Research Institutions. Bulletin of Chinese Academy of Sciences, 4, 274-303.

[18] Zhang, F. and Huo, G.Q. (2007) An Evaluation Model of Innovative Efficiency on National Research Institutes. Science Research Management, 2, 55-59.

[19] Zhuang, L.X., Xu, Y.P. and Zhang, M.H. (2015) Study on the Cultivation and Development Countermeasures of the New R \& D Institutions. Innovation Science \& Technology, 10, 16-17.

[20] Dong, J.Z. (2012) Institutional Mechanism Innovation of New R \& D Institutions. Practice and Theory of SEZS, 6, 28-32. 